\title{
Socio Cultural Taboos and Restrictions during Menstruation followed by School going Adolescent Girls in a Semi Urban Area of Jaipur, Rajasthan
}

\author{
Samar Hossain 1 , Vandna Sen² \\ ${ }^{1}$ Department of Community Medicine, G.S Medical College \& Hospital, Hapur, U.P, INDIA \\ ${ }^{2}$ Department of Community Medicine, NIMS University, Jaipur, Rajasthan. INDIA
}

\begin{abstract}
Received: 1 August 2017; Accepted: 25 September 2017

*Correspondence to:

Dr. Samar Hossain, MBBS,

MD (Community Medicine), Assistant Professor, Department of Community Medicine, G.S Medical College \& Hospital, Hapur, U.P, India. Email:samy.delhidoc@gmail.com

Copyright: $\odot$ the author(s),publisher and licensee Indian Academy of Pharmacists. This is an openaccess article distributed under the terms of the Creative Commons Attribution Non-Commercial License, which permits unrestricted non-commercial use, distribution, and reproduction in any medium, provided the original work is properly cited.
\end{abstract}

Publishing Partner : EManuscript [www.emanuscript.in]

\begin{abstract}
Objective: With this background the present study was designed as an attempt to unfurl the taboos related to menstruation prevalent amongst school going adolescent girls in a rural area. Methods: The present study was conducted among girl's middle and high schools of Achrol village which is a rural field practice area (RHTC) of NIMS. Study population included all adolescent school going girls of 10-19 years age group residing in Achrol vilage, Jaipur. Results: The study concluded that out of the 400 girls selected for the study, 325 were not allowed to enter the kitchen or cook food during menstruation. A majority i.e. $85 \%$ of the adolescent girls were not allowed to touch the pickle jar. Conclusion: It was concluded that unless the myths, misconceptions and customs which go against the girl child are changed it will be difficult to improve the nutritional, health, economic and social status of the girls.
\end{abstract}

Key words: Menstruation, Adolescent girls, Taboos, Beliefs, Patterns.

\section{INTRODUCTION}

Menarche is an abrupt signal that marks a change in social status from child to adult. Cross- culturally there is a wide range of significance attached with menarche. The attitude of societies towards menarche varies from delight and pride to fear and shame. The two main religions in India i.e. Hinduism and Islam, are the roots of many of these social customs and beliefs. ${ }^{[1]}$

In various parts of India, there are several cultural traditions, myths and misconceptions related to menstruation, which make them vulnerable to genital tract infections. According to a study by Mudey et al in Wardha district, India (2010), ${ }^{[2]}$ menstruation is generally considered unclean leading to isolation of the menstruating girls and restrictions imposed on them by the family. In India, certain taboos are followed, for example once the menstruation begins the girl is isolated from participating in day to day activities, first she should take a bath as soon as she wakes up from sleep for which there is a separate place where she has to take a separate mat for sleeping which should be washed every day. She isn't allowed to visit the temple, she shouldn't touch flowers, she shouldn't cook food or enter the kitchen. This practice was very strong in urban areas compared to rural areas. ${ }^{[3]}$ In another study carried out by Nair $e t$ al in 2007 , it was observed that $92 \%$ of the girls were restricted from worshipping, $70 \%$ were 
restricted in participating in household activities and 56\% of the girls were not allowed to eat oily, cold or spicy food during menstruation. ${ }^{[4]}$ M.Sarika et al (2015) conducted a study among 100 Muslim females in Banihal,J\&K and observed that $74 \%$ of the females faced restrictions related to food during menstruation. ${ }^{[5]}$

\section{METHODS}

The study population included all adolescent school going girls of 10-19 years age group, residing in the field practice area of RHTC, Achrol. The study began in January 2015, till the estimate sample size was achieved that is in June 2016. The calculated sample size came out to be 288 adolescent girls, however it was decided to include 400 girls who were studying in Government and Private schools in Achrol. Ethical approval was granted by the ethical committee of NIMS Medical college and Hospital, Jaipur before the beginning of the study. Verbal and written consent was taken from each participant in the study.

\section{RESULTS AND DISCUSSION}

$174(43.5 \%)$ who did not have any restrictions as shown in Figure 1. Figure 2 shows the restrictions regarding entry in the kitchen were seen in 75 (18.8\%) girls, religious restrictions during menstruation were seen in 226 (56.5\%) girls, whereas restrictions in physical activity during menstruation were seen in $220(55.0 \%)$ adolescent girls.

Figure 3 shows distribution of adolescent girls according to their sleeping pattern during menstruation. 311 (77.7\%) girls were allowed to sleep on the bed with a mattress, whereas $83(20.8 \%)$ adolescent girls were made to sleep on a cot during menstruation. Subash et al (2011)38 and Sarika et al (2015) 86 while studying the restrictions faced by the adolescent girls during menstruation observed that $73.6 \%$ and $71.0 \%$ of the adolescent girls were allowed to sleep on the normal cot, which is quite similar to the observations made in the present study. On enquiring about cooking food, maximum number of the adolescent girls i.e. 325 $(81.2 \%)$ said that they were allowed to cook food during menstruation as depicted in Figure 4.

Table1 shows distribution of girls according to practices during menstruation. 340 (85\%) girls were not allowed to touch pickle due to fear of being spoilt. Whereas $236(59 \%)$ were allowed to touch the food once it was cooked.

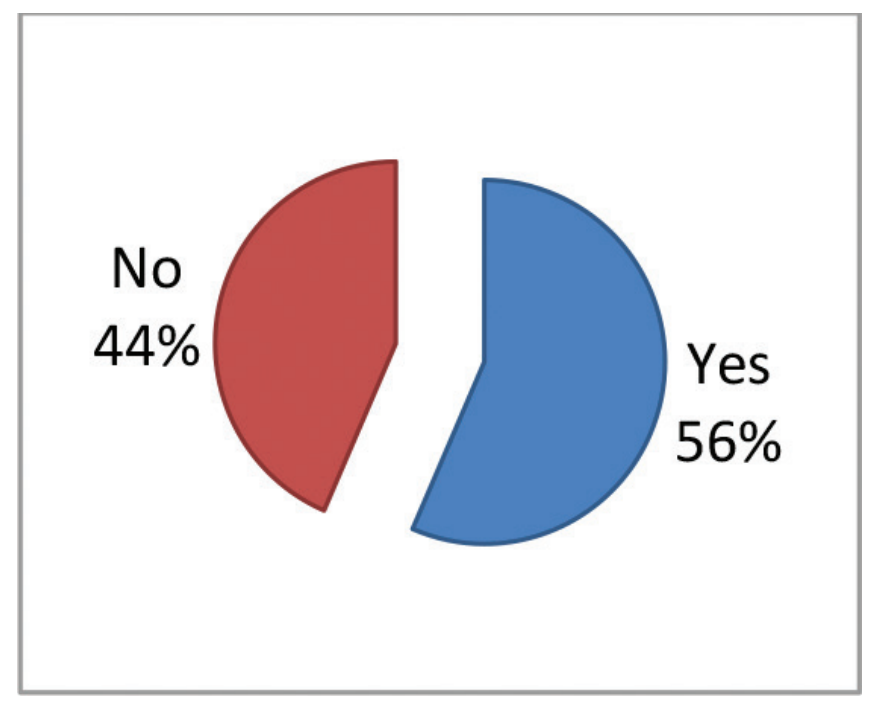

Figure 1: Distribution of adolescent girls according to rituals followed during menstruation

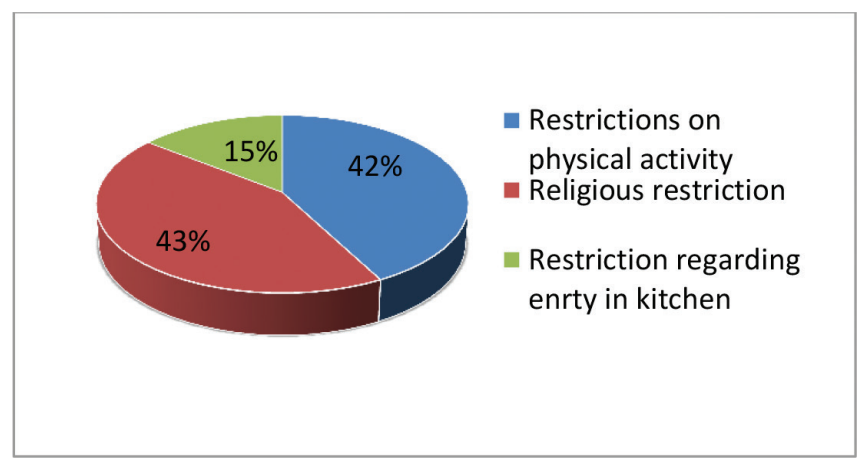

Figure 2: Nature of taboos

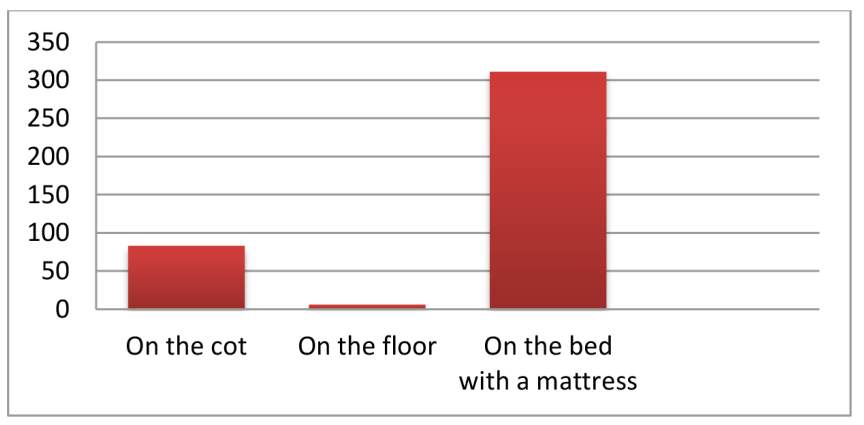

Figure 3: Distribution of adolescent girls according to their sleeping pattern during menstruation

\section{CONCLUSION}

Community awareness and involvement will be one of the important components of the Rajiv Gandhi scheme for empowerment of adolescent girls- SABLA. Unless the myths, misconceptions and customs which go against the girl child are changed it will be difficult to improve 
Hossain et al : Study about socio cultural factors during menstruation among school going girls

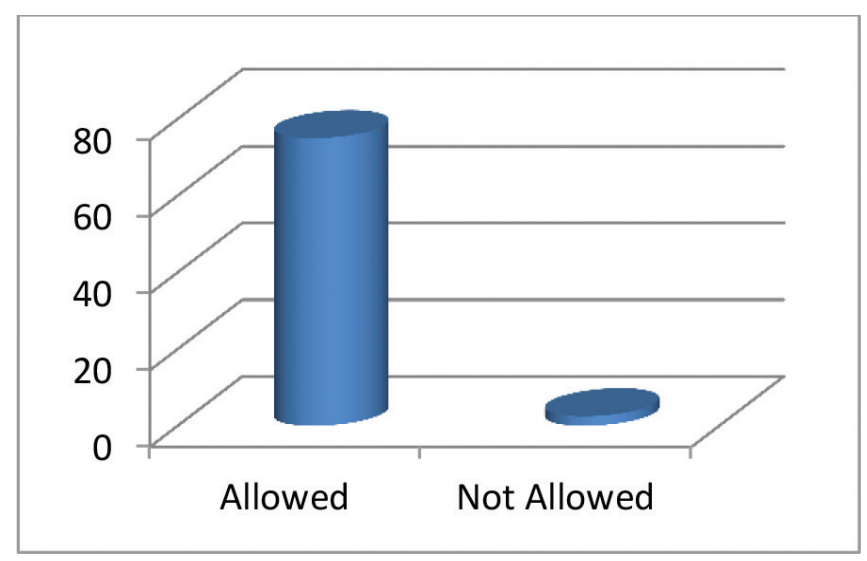

Figure 4: Cooking of food during menstruation

\begin{tabular}{lll}
\hline $\begin{array}{l}\text { Table 1: Distribution of girls according to practices } \\
\text { during menstruation }\end{array}$ & \\
\hline During menstruation & Allowed & Not Allowed \\
\hline Touching cooked food & 236 & 164 \\
Touching the pickle jar & 60 & 340 \\
\hline
\end{tabular}

the nutritional, health, social and economic status of the adolescent girl. To achieve this involvement of Panchayats in improving awareness level of the community will be desirable. Sensitization programs for parents, adolescents and community may be taken under IEC by involving NGOs/CBOs/Civil society organization/PRIs.

\section{Acknowledgement: None}

Competing interests: None declared

\section{Funding: None}

Abbreviations: None

\section{REFERENCES}

1. Hossain S, Sharma P, Sen V. A Study of the Knowledge and Practice Regarding Menstrual Hygiene in Rural Adolescent School Going Girls in an Indian Cosmopolitan City. J Pharm Practice Community Med. 2017;3(3):185-7.

2. Mudey AB, Kesharwani N, Mudey GA, Goyal RC. A cross sectional study on awareness regarding safe and hygienic practices amongst school going adolescent girls in rural area of Wardha district, India, Global J Health Sci. 2010;2(2),225-31.

3. Selvi KT, Ramachandran S. Socio cultural taboos concerning menstruation-A micro level study in the cuddalore district of Tamil Nadu, India, IJSRP. 2012;2(8):1-7.

4. Nair P, Grover VL, Kannan AT. Awareness and practices of menstrual and pubertal changes amongst unmarried female adolescents in a rural area of East Delhi. Indian J Community Med 2007;32(2):156-7.

5. Manhas, S, Salem, R. A study of menstrual taboos prevalent among Muslim females of Banihal, J and K. Inter J Recent Scientific Res. 2015;6(7):4930-4.

Cite this article as: Hossain S, Sen V. Socio cultural taboos and restrictions during menstruation followed by school going adolescent girls in a semi urban area of Jaipur, Rajasthan. J Pharm Pract Community Med. 2017;3(4):285-7. 